\title{
ANALYSIS BY SIMULATION OF THE FRACTIONAL FACTORIAL DESIGN OBTAINED BY THE EXPERIMENTAL AND THE NUMERICAL METHOD
}

ALBERT MIYER SUAREZ ${ }^{1}$, THOMAS EDISON GUERRERO ${ }^{2} \&$ SIR-ALEXCI SUAREZ $^{3}$

\author{
${ }^{1}$ Faculty of Engineering and Architecture. University of Pamplona, Colombia. \\ ${ }^{2,3}$ Engineering Faculty, University Francisco of Paula Santander Ocaña, Colombia
}

\begin{abstract}
In this research we present the experimental and simulation development of the variables that can influence the dimension of the piece, through the molding process. It is made an analysis by simulation of the fractional factorial design $2^{5-1}$ and the influence of the type of mesh and the number of elements that compose it, on the output variables or answers of obtained quality, and the answers on contraction and compaction in the quality of the dimension.
\end{abstract}

KEYWORDS: Moulding simulation, design of experiments, quality control

Received: Nov 27, 2020; Accepted: Dec 18, 2020; Published: Dec 24, 2020; Paper Id.: IJMPERDDEC202073

\section{INTRODUCTION}

The industry of manufacturing injection molded parts is growing day by day, so its level of demand increases as the fields of application and competitiveness of this type of industry expand; therefore, it is necessary to use systematic methods, for control and optimization so that through these methods, the processing windows of the molding process can be established more precisely and quickly (Martín del Campo et al., 2016; Rosales et al., 2018).

The design of experiments consists of planning a set of experimental tests, so that the data generated can be statistically analyzed to obtain valid and objective conclusions about the process (Gutiérrez Pulido \& Salazar, 2012). For the execution of a design of experiments, the order in which the experiments will be developed must be planned and established, selecting the appropriate levels, as well as the combination of those factors that intervene in the experiment (Ramos Jaubert et al., 2011), to analyze their change and interaction in order to be able to be treated statistically later and thus generate a response.

The design of the experiment will be used to look for the influence of certain factors on the shrinkage and weight that the pieces present after their injection and expulsion, since these two characteristics are known to be key in the dimensional stability of the final piece (Barra García, 2014). The application of the design of experiments will have as main objective the minimization of the contractions in the injected pieces, according to the best combination of parameters achieved. The design of experiments is qualified as statistical, since it allows selecting the most appropriate experimental strategy for each case. Additionally, before recording any data, it can be verified that the chosen plan has the possibilities to correctly identify and quantify the importance of the input factors.

These studies of interaction between factors and the influence they exert on the quality response in the parts produced by the molding process, would require many tests, investment of material, time and money; that would not make them feasible to carry out, since the number of tests required, for the experimentation tends to grow as the 
amount of factors increases, even more if their interrelationship was studied at higher order levels.

One of the most important achievements in engineering, is to be able to explain by means of mathematical models, the physical processes, in our case the modeling of the plastic flow and its route through channels, ducts and the filling of the respective mold, giving origin to the computational software, very common in our days and that advises the task of the molding machine, giving more reliable and fast results, according to the demand and accuracy of the shaped model (AG, 2001; Duesseldorf, 1989). One of the critical stages in the injection process is the filling stage (Benítez-Rangel et al., 2012; Yznaga et al., 2015), and as the molded parts have complex shapes and are three-dimensional and the flow is non-newtonian and non-isothermal, it is essential for the development a simplification for the success of the simulation tool in this stage.

This research presents a simulation analysis of the fractional factorial design of the variables that most influence the dimensional characteristics of the parts.

\section{METHODOLOGY}

The methodology of simulation analysis of fractional factorial design ${ }^{25-1}$ comprises: an analysis of input and output variables and their influence on dimensional quality responses (shrinkage, compaction). Analysis of the influence of the type of mesh and the number of elements that compose it, on quality responses obtained and a comparative analysis between the responses obtained by the experimental method and the numerical method obtained through simulation. According to the above, an analysis and discussion of the variables that most influence the dimensional characteristics, their operating region according to the respective result equations and graphs will be presented.

In Table 1, the experimental results of the design of experiments ${ }^{25-1}$ and the analysis corresponding to the main effects of the variables on the response of dimensional quality measured longitudinally, transversally and weight measurement are presented.

Table 1: Material ABS Magnum. Simulated ${ }^{25-1}$ Factorial Design Response

\begin{tabular}{|c|c|c|c|c|c|c|}
\hline \multicolumn{7}{|c|}{ ABS Magnum 3325MT No. of Elements 1995 Mesh size 1.72 mm } \\
\hline \multirow{2}{*}{ Experiment } & $\begin{array}{c}\text { Volumetric } \\
\text { Shrinkage \%. }\end{array}$ & $\begin{array}{c}\text { Cold } \\
\text { Layer \%. }\end{array}$ & $\begin{array}{c}\text { Shrinkage (X) } \\
(\mathbf{m m})\end{array}$ & $\begin{array}{c}\text { Shrinkage (Y) } \\
(\mathbf{m m})\end{array}$ & $\begin{array}{c}\text { Global } \\
\text { Shrinkage } \\
(\mathbf{m m})\end{array}$ & Weight (g) \\
\hline $\mathbf{1}$ & 6,0505 & 1,0000 & 0,2012 & 0,1349 & 0,2340 & 2,5363 \\
\hline $\mathbf{2}$ & 6,2231 & 1,0000 & 0,1911 & 0,1315 & 0,2207 & 2,5316 \\
\hline $\mathbf{3}$ & 6,0742 & 1,0000 & 0,2019 & 0,1357 & 0,2346 & 2,5357 \\
\hline $\mathbf{4}$ & 6,2241 & 1,0000 & 0,1914 & 0,1310 & 0,2206 & 2,5316 \\
\hline $\mathbf{5}$ & 6,0026 & 1,0000 & 0,1997 & 0,1347 & 0,2320 & 2,5376 \\
\hline $\mathbf{6}$ & 6,1973 & 1,0000 & 0,1906 & 0,1299 & 0,2206 & 2,5323 \\
\hline $\mathbf{7}$ & 6,0371 & 1,0000 & 0,2010 & 0,1342 & 0,2336 & 2,5366 \\
\hline $\mathbf{8}$ & 6,2197 & 1,0000 & 0,1913 & 0,1299 & 0,2213 & 2,5317 \\
\hline $\mathbf{9}$ & 5,0395 & 1,0000 & 0,1698 & 0,1127 & 0,1967 & 2,5636 \\
\hline $\mathbf{1 0}$ & 5,2325 & 1,0000 & 0,1629 & 0,1100 & 0,1877 & 2,5584 \\
\hline $\mathbf{1 1}$ & 5,0563 & 1,0000 & 0,1705 & 0,1118 & 0,1977 & 2,5631 \\
\hline $\mathbf{1 2}$ & 5,2560 & 1,0000 & 0,1637 & 0,1092 & 0,1869 & 2,5577 \\
\hline $\mathbf{1 3}$ & 5,0949 & 1,0000 & 0,1713 & 0,1161 & 0,1977 & 2,5621 \\
\hline $\mathbf{1 4}$ & 5,3361 & 1,0000 & 0,1656 & 0,1147 & 0,1902 & 2,5556 \\
\hline $\mathbf{1 5}$ & 5,0746 & 1,0000 & 0,1708 & 0,1140 & 0,1982 & 2,5626 \\
\hline $\mathbf{1 6}$ & 5,3276 & 1,0000 & 0,1656 & 0,1130 & 0,1908 & 2,5558 \\
\hline
\end{tabular}


The response of dimensional quality in the measure of the analyzed piece, the longitudinal measure of the same one was taken and only the significant effects were taken into account to carry out the respective analysis of variance

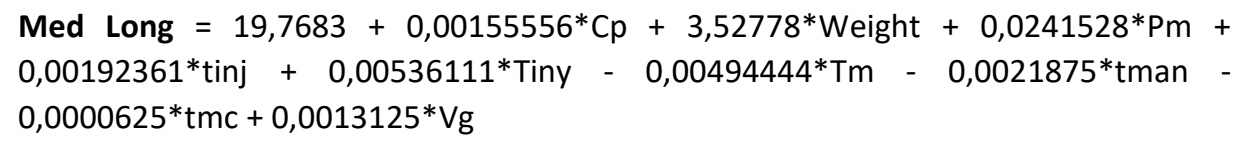

\section{Experiment Design Matrix ${ }^{25-1}$}

In Table 2, the matrix of the design of experiments ${ }^{25-1}$ is presented, which implies the analysis of 5 factors, coded between $-1,0,1$, both in its standard order and in random order. It is worth mentioning that the analysis of the answers must be done with the matrix placed in standard form, because when varying the order of the analysis of the answers, or analyzing the matrix placed in random order, the effects produced by the variables involved will also vary, making the respective analysis erroneous.

Table 2: Fractional Experiment Design Matrix ${ }^{25-1}$

\begin{tabular}{|c|c|c|c|c|c|c|c|}
\hline $\begin{array}{c}\text { Experimental } \\
\text { or Replica } \\
\text { Number }\end{array}$ & $\begin{array}{c}\text { Random } \\
\text { Order }\end{array}$ & $\begin{array}{c}\text { Standard } \\
\text { Order }\end{array}$ & A:Tiny & B:Tm & C:tinj & D:Pm & E=tman \\
\hline 1 & 1 & 1 & -1 & -1 & -1 & -1 & 1 \\
\hline 1 & 5 & 2 & 1 & -1 & -1 & -1 & -1 \\
\hline 1 & 13 & 3 & -1 & 1 & -1 & -1 & -1 \\
\hline 1 & 9 & 4 & 1 & 1 & -1 & -1 & 1 \\
\hline 1 & 6 & 5 & -1 & -1 & 1 & -1 & -1 \\
\hline 1 & 2 & 6 & 1 & -1 & 1 & -1 & 1 \\
\hline 1 & 10 & 7 & -1 & 1 & 1 & -1 & 1 \\
\hline 1 & 14 & 8 & 1 & 1 & 1 & -1 & -1 \\
\hline 1 & 3 & 9 & -1 & -1 & -1 & 1 & -1 \\
\hline 1 & 7 & 10 & 1 & -1 & -1 & 1 & 1 \\
\hline 1 & 15 & 11 & -1 & 1 & -1 & 1 & 1 \\
\hline 1 & 11 & 12 & 1 & 1 & -1 & 1 & -1 \\
\hline 1 & 8 & 13 & -1 & -1 & 1 & 1 & 1 \\
\hline 1 & 4 & 14 & 1 & -1 & 1 & 1 & -1 \\
\hline 1 & 12 & 15 & -1 & 1 & 1 & 1 & -1 \\
\hline 1 & 16 & 16 & 1 & 1 & 1 & 1 & 1 \\
\hline
\end{tabular}

\section{General Characteristics and Proposed Objectives. Experiment design matrix ${ }^{25-1}$}

In this design of experiments, its analysis was carried out in a complete way, with the specific objective of analyzing: influence of the factors on the analyzed responses, variability of the process, curvature analysis, etc.

The 5 factors studied were selected according to the existing theory and the analysis of importance on the influence that these variables exerted on the quality responses, such as the dimensional stability and the weight (compaction) of the piece.

- Injection temperature (mass); (Tiny)

- $\quad$ Mold Temperature; (Pm)

- Injection time; (tinj)

- Holding pressure; (Pm)

- Maintenance time; (tman) 


\section{RESULTS}

The main objective of this experimental development by means of process simulation in the MPI 4.1 software, was to determine and analyze the input variables that most influence the injection process when determining the processing conditions and importance on the dimensional and weight (shrinkage and compaction) quality responses and their correlation. The output variables obtained through the simulation of the process will also be evaluated, since these variables indicate an effect to be produced on the final part, and their analysis is very important to correlate them with the defects produced in the molded part. These effects will be analyzed only on the basis of the influence they have on the dimensional measurements, since the software gives us a direct and approximate reading of the weight response.

The comparison of this experimental group by means of simulation will be done as in part I, graphically and mathematically. The analysis in this part of the experimental development was made, with a fractioned experiment design, and involved the study of 5 variables. In this fractional factorial design, variability was studied, as well as the influence of the type of mesh and also of the number of elements that compose it, on the different responses obtained, in order to determine which was the most adequate mesh density when studying different types of quality responses, in this case on the dimensional and weight quality (Figure 1 and 2).

Finally, a comparison will be made between the responses obtained by simulation and those obtained experimentally, to determine the type of correlation that exists. This comparison will be done graphically and mathematically, coding the answers obtained to obtain a greater clarity of the process and to be able to establish a relationship, when approaching the injection molding process in a systematic and methodical way (table 3 ).

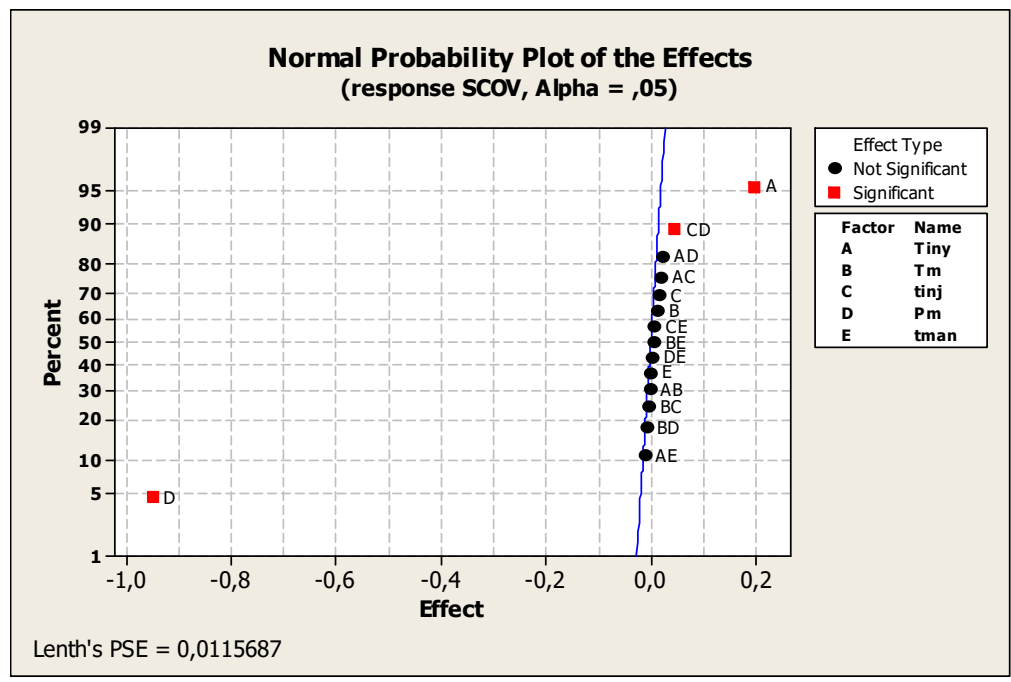

Figure 1: Probability Normal VOC simulation 


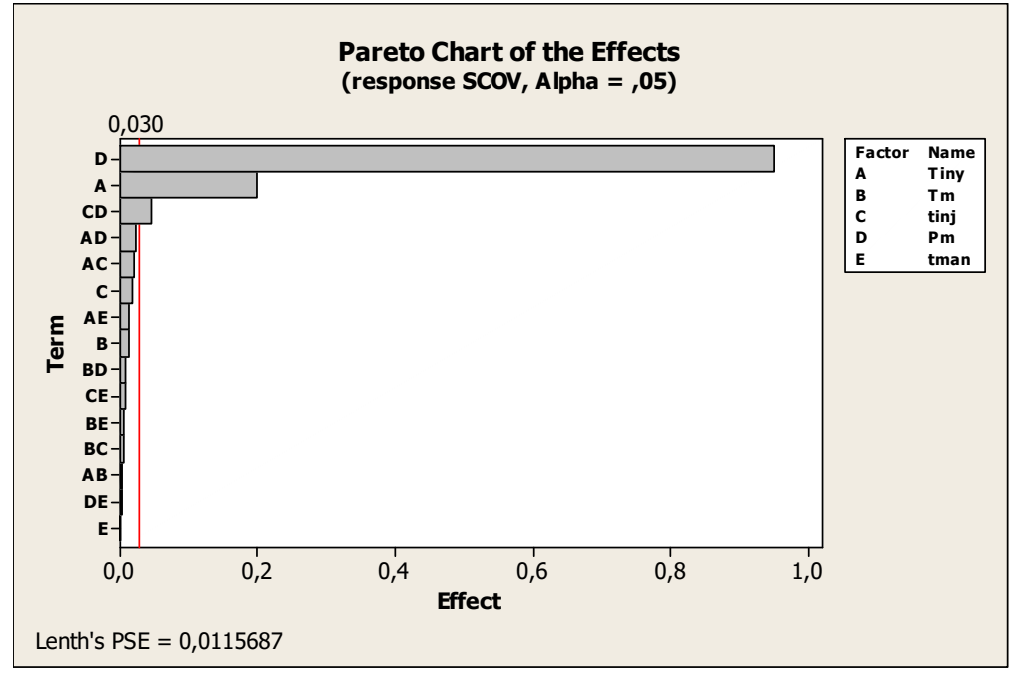

Figure 2: VOC Pareto

Table 3: Significant effects Volumetric contraction SCVO

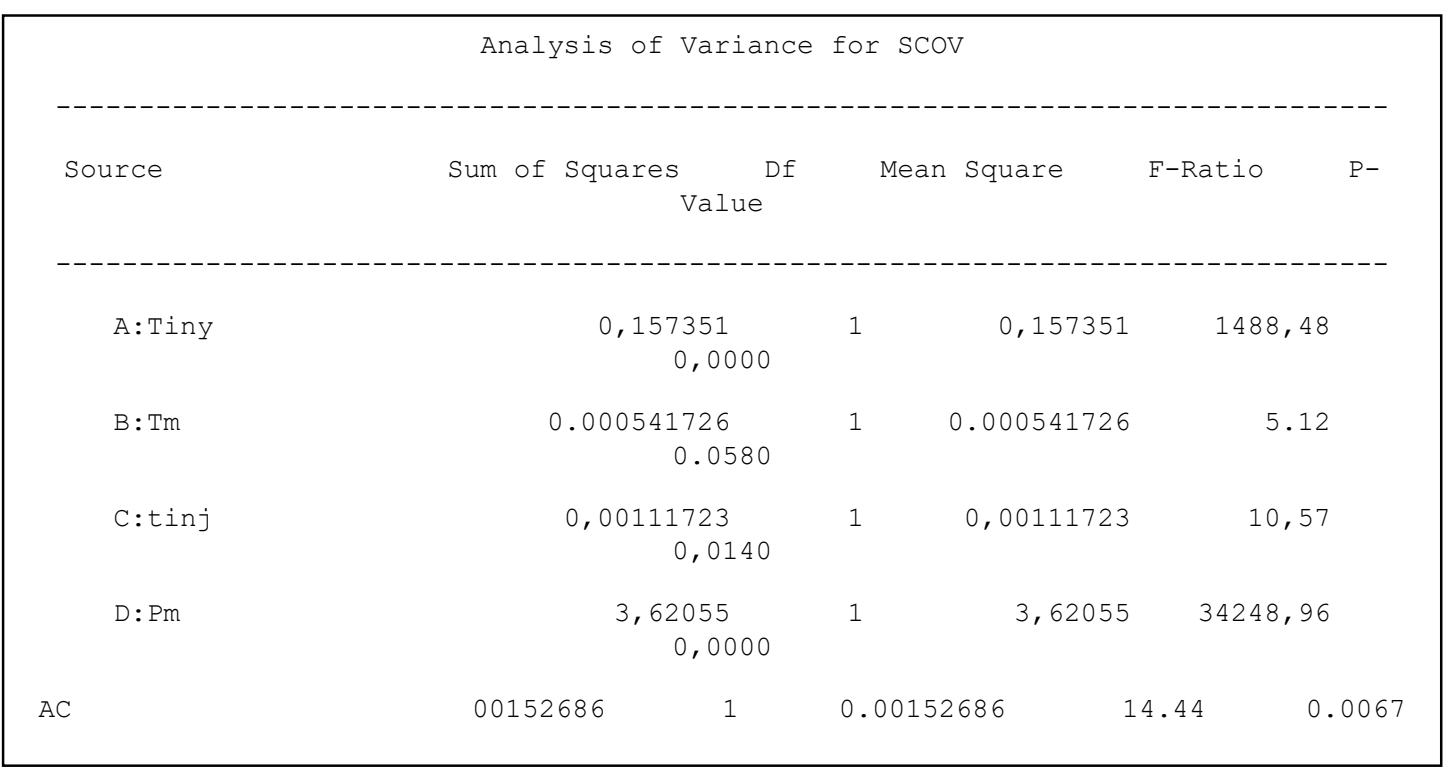

- $\quad$ The ${ }^{88-4}$ factorial arrangement was not made by means of simulation since there were some parameters to input variables, which could not be evaluated at a numerical level such as; the counter pressure, the spindle speed.

- $\quad$ This analysis design was made at the machine mainly to determine which of the variables used in the ${ }^{28-4}$ factorial design, influenced the quality characteristics. For our interest, the quality study was carried out only at the dimensional and compaction level. Other dimensional defects such as burns, moisture, bursts, air bubbles, flow lines, will not be addressed by the study, as it would imply the application of other experimental techniques.

\section{CONCLUSIONS}

The simulation of molding processes helps considerably to know the defects of the pieces, as well as to improve the precision of the dimension of each one. By means of an experimental analysis it is possible to know the influence of certain variables in the final result, decreasing the time in the production and increasing the quality levels in all the areas of the industry. The 
design of experiments is fundamental to check the results of a simulation.

\section{REFERENCES}

1. AG, B. (2001). Injection Molding: Process Control. Informador Técnico, 63, 50. https://doi.org/10.23850/22565035.955

2. Barra Garcia, R. (2014). Dimensional variations in plastic injection pieces and analysis of control means. http://dspace.uvic.cat/xmlui/handle/10854/3227

3. Benitez-Rangel, J. P., Morales-Hernández, L. A., \& Trejo-Hernández, M. (2012). Improvement of the filling stage in plastic injection molds using vibration. Engineering. Research and Technology, XIII(4), 403-410.

4. Duesseldorf, B. (1989). Increase of productivity in the injection of technical plastic materials. Technical Informant, $40,1$. https://doi.org/10.23850/22565035.1242

5. Gutiérrez Pulido, H., \& Salazar, R. (2012). Analysis and Design of Experiments. In SERBIULA (Librum 2.0 system).

6. Martín del Campo, R., Colunga, C., Almanza, R., Yáñez, P., \& Enríquez, V. (2016, September 28). CAD development and manufacture of a prototype mold for plastic injection.

7. Ramos Jaubert, R., Chávez, J., \& R, R. (2011, October 15). Research designs and experiments in the scientific researcher. https://doi.org/10.13140/RG.2.1.1179.8803

8. Rosales, I. B., Sanchez, G. G. M., Gil, J. A. M., Reynoso, M. del R. F., \& León, R. R. arbitrated by the U. T. de. (2018, May 29). Additive manufacturing, a current production alternative (Tecnológico de Estudios Superiores de Jocotitlán) . Reaxion. Arbitrated magazine of scientific popularization of the Universidad Tecnológica de León. http://reaxion.utleon.edu.mx/Art_Manufactura_aditiva_una_alternativa_de_produccion_actual.html

9. Yznaga, H., Ortiz, J., Avalos, F., Tellez-Rosas, M., \& Aguirre Flores, R. (2015). Models for injection molding simulation: Review and comparison. Revista Iberoamericana de Ciencias, 2, 143. 